\title{
Kajian Routing pada Framework Laravel 5.0 dari Perspektif Penggunaan
}

\author{
Yusup Miftahuddin, Muhammad Ichwan, Achmad Zaky \\ 1Program Studi Teknik Informatika, Fakultas Teknologi Industri \\ Institut Teknologi Nasional - Bandung \\ Email: yusufm@itenas.ac.id
}

\begin{abstract}
ABSTRAK
HTTP routing merupakan suatu cara untuk menangani pemetaan URL dalam aplikasi web. Dari situs laravelbook.com dijelaskankomponen Laravel memiliki penambahan yaitu blok routing, dibandingkan dengan Symfony yang merupakan pendahulunya. Laravel menyediakan pendekatan painless routing (dari situs laravel.com) untuk menerapkan routing pada aplikasi web.Laravel pada situs resminya tidak menjelaskan secara mendetail mengenai konsep routing. $\mathrm{Hal}$ tersebut yang menjadi fokus penelitian untuk mengkaji syarat, fungsi dan peran, cara kerja, dan apa yang menjadi kelebihan dan kekurangan dengan fitur-fitur routing pada Laravel versi 5.0. Peneliti melakukan pengujian mengukur jumlah langkah pembuatan URI terhadap routing Laravel dan cara konvensional yang menyerupai routing Laravel, hasilnya Laravel memiliki langkah sekali deklarasi dibandingkan secara konvensional. Peneliti tidak menemukan kekurangan dari pengunaan routing pada Laravel tetapi developerharus memahami konsep routing pada Laravel tersebut sebagai konsekuensinya.
\end{abstract}

Kata kunci: Laravel, Laravel 5.0, Routing, Routing Laravel, HTTP Routing.

\begin{abstract}
HTTP routing is a way to handle URL mappings in the web application. From the site of laravelbook.com described laravel have additional routing component, compared with Symfony which is the predecessor. Laravel provide painless approach routing (from laravel.com sites) to implement routing in a web application. Laravel on the official website did not elaborate on the concept of routing. This is exactly the focus of research to assess the requirements, functions and role, ways of working, and what the advantages and disadvantages with routing features on laravel version 5.0. Researchers conducted a test to measure the number of steps for making URI against laravel routing and conventional ways that resemble routing laravel, laravel result has once steps than conventional declarations. Researchers did not find the lack of use of the routing on laravel but developers must understand the concept of routing on the laravel as a consequence.
\end{abstract}

Keywords: Laravel, Laravel 5.0, Routing, Laravel's Routing, HTTP Routing. 


\section{PENDAHULUAN}

Dalam membangun tradisional web diperlukan membuat direktori (atau virtualdirektory pada IIS) untuk mengatur peta URL pada web server. Hal itu tidak akan menjadi masalah jika direktori-nya bukan merupakan parameter. Pengembangan web semacam ini memiliki batasan karena setiap parameter perlu dibuat direktorinya begitupun dalam pengelolaannya, diperlukan suatu sistem yang dapat menutupi celah permasalahan tersebut. Permasalahan ini dapat ditangani dengan http routing.

Pada tahun 2015 SitePoint, sebuah perusahaan training online melakukan survey mengenai framework PHP yang digunakan pada tahun 2015, yang mana framework Laravel menjadi framework PHP yang paling diminati dalam pengerjaan proyek di tempat bekerja maupun proyek pribadi [1]. Dari hasil survey tersebut membuat penulis tertarik untuk meneliti lebih dalam lagi Laravel, yang mana versi waktu keluarnya hasil survey adalah 5.0. Framework PHP Laravel dibangun dari framework PHP Symfony.

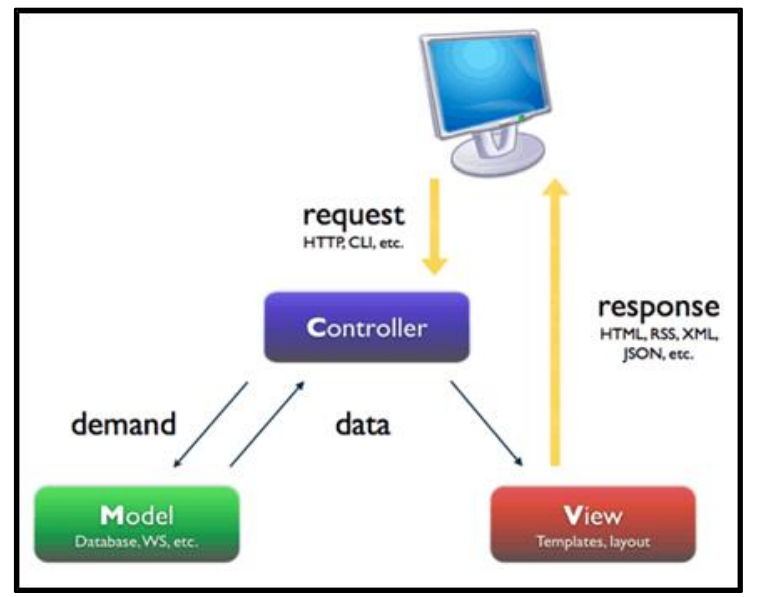

Gambar 1. Komponen pada framework PHP Symfony (Potencier, 2005)

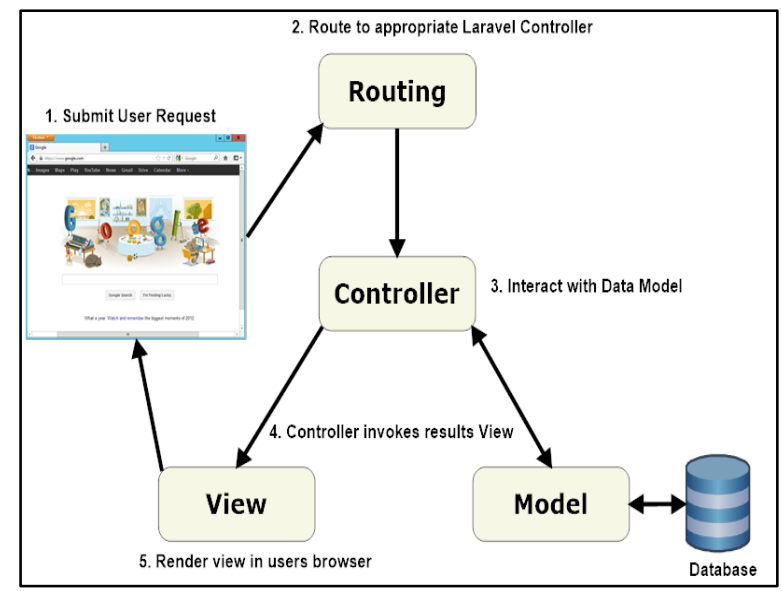

Gambar 2. Komponen pada framework PHP Laravel (Ehsan, 2013)

Gambar 2 menjelaskan bahwa framework Laravel memiliki penambahan komponen yaitu blok routing. Laravel pada situs resminya https://laravel.com/docs/5.0/routing tidak dijelaskan secara rinci mengenai routing, pada situs resmi tersebut dijelaskan cara penggunaan dari fitur-fitur routing Laravel. Hal tersebut yang menjadi fokus penelitian untuk mengkaji syarat, fungsi dan peran, cara kerja, dan apa yang menjadi kelebihan dan kekurangan dengan routing pada framework Laravel khususnya versi 5.0. 
Penelitian ini diharapkan dapat menjadi referensi dalam mengkaji dan memahami fungsi dan penggunaan routing pada framework PHP lainnya terutama framework PHP Laravel.

\section{METODOLOGI PENELITIAN}

\subsection{Studi Literatur}

Literatur yang digunakan adalah yang terkait dengan MVC, routing pada MVC, dan framework Laravel 5.0. Pembelajaran dilakukan dengan mencari referensi yang diperoleh dari buku dan media online yang diantaranya https://laravel.com/docs/5.0.

\section{ANALISIS DAN PEMBAHASAN}

Aspek yang dikaji pada penelitian ini adalah:

1. Syarat untuk menggunakan routing pada Laravel

2. $\quad$ Fungsi atau peran routing pada Laravel

3. Bentuk atau parameter yang harus dipenuhi dari routing pada Laravel

4. $\quad$ Fitur dari routing pada Laravel

5. Cara kerja routing pada Laravel

Untuk mengkaji kelima aspek tersebut dibangun sebuah aplikasi. Aplikasi menggunakan framework laravel 5.0. Selain dikaji kelima aspek tersebut dengan aplikasi, penulis juga melakukan studi banding antara routing dengan menggunakan Laravel dan cara yang menyerupai pembuatan routing dengan menggunakan Laravel (secara konvensional). Hal itu dilakukan untuk mengukur jumlah proses dalam membangun routing pada Laravel. Studi banding secara konvensional yang dibandingkan ada dua yaitu membangun URI mengunakan skrip dan tanpa menggunakan skrip. Untuk itu juga diperlukan membangun aplikasi pengujiannya.

Yang dibandingkan pada studi banding dalam penelitian ini meliputi:

1. Membuat URI aplikasi web

2. Membuat URI berparameter

3. Mengaliaskan URI

4. Mengelompokkan URI

5. Membuat URI untuk proses CRUD

\subsection{Aspek yang dikaji}

\subsubsection{Syarat untuk menggunakan routing pada Laravel}

Pada tahap ini adalah mengkaji syarat-syarat yang harus dipenuhi dalam menggunakan routing. Pengkodean routing secara default berada di file app/Http/routes.php, yang dimuat oleh kelas App\Providers\RouteServiceProvider yang berada pada file App \Providers $\backslash$ RouteServiceProvider.php. File tersebut merupakan file untuk route yang dijalankan pada saat menggunakan aplikasi web pada browser. Dari hal tersebut baru dapat dilakukan pendefinisian route, untuk mendefinisikannya harus menggunakan kelas Route.

\subsubsection{Fungsi atau peran routing pada laravel}

Routing pada Laravel berfungsi untuk menangani semua URL requested pada aplikasi web. Terdapat dua peran routing pada Laravel, yaitu: 
1. Sebagai diri sendiri(routing), routing pada peran ini adalah sebagai penghubung antara browser dengan kelas controller aplikasi web. Pada Gambar 2 ditunjukkan peran routing pada Laravel sebagai routing. Ketika user men-submit permintaan pada web browser maka akan diterima oleh routing, routing akan mengeksekusi route yang sesuai permintaan URL dan menunjuk controller yang mana beserta action-nya, dari controller tersebut pada action-nya kode program akan dijalakan, dimana akan berinteraksi dengan Model, routing akan menghasilkan keluaran untuk ditampilkan menggunakan View, pada tahap terakhir dibuat tampilan ke browser user.

2. Sebagai controller, routing pada Laravel merupakan bagian dari controller, tetapi routing bisa dibangun tanpa memerlukan kelas controller.

\subsubsection{Bentuk atau parameter yang harus dipenuhi dari routing pada laravel}

Bentuk route yang paling sederhana terdiri dari URI dan closure.URI disini dapat berupa "/" yang artinya nama host -nya, atau antara URI satu dengan yang lainnya dipisahkan dengan tanda "/". Closure disini terdiri dari nama kelas controller dan action, dimana action merupakan function yang didefinisikan dalam nama kelas controller tersebut. Cara penulisan atau deklarasinya adalah "NamaKelasController@action"; Function langsung pada saat mendeklarasikan route.

\subsubsection{Fitur dari routing pada laravel}

Laravel menghadirkan routing dengan berbagai fitur, hal ini membuat pengembang aplikasi dapat leluasa dalam membangun aplikasinya. Berikut adalah fitur routing dalam Laravel, yaitu:

1. Menggunakan HTTP Verb yaitu get, post, put, dan delete. Selain itu juga dapat merupakan gabungan beberapa verb, atau mewakili semua verb.

2. Memiliki satu parameter, atau lebih.

3. Menggantikan routing dengan nama yang diinginkan dengan mengaliaskannya.

4. Mengelompokkan routing sehingga suatu route dapat memiliki banyak route. Dapat mengelompokkan berdasarkan namespace, atau memberikan hak akses dengan middleware.

5. Route sebagai controller yaitu menggantikan posisi controller dimana sintaks program dituliskan pada route.

6. Didefinisikan satu kali, untuk banyaknya action dari sebuah controller, yang dikenal dengan implicit controller.

7. Didefinisikan satu kali, untuk kebutuhan CRUD pada sebuah controller.

\subsubsection{Cara kerja routing pada laravel}

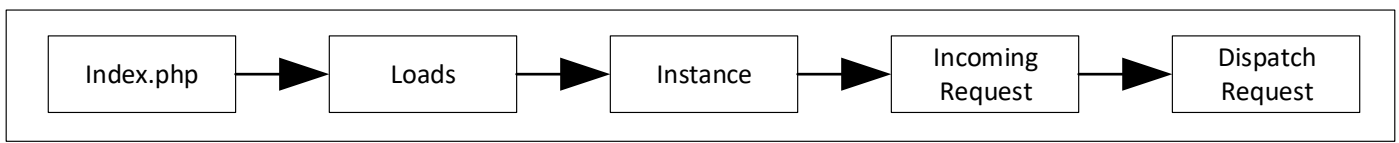

Gambar 4. Request lifecycle dari Laravel 5.0("Laravel 5 request lifecycle", 2016)

Tahap terakhir(pada Gambar 4) dispatch request(mengirim request), Setelah aplikasi telah bootstrapped dan semua service provider telah terdaftar, request akan diserahkan ke router(pada Gambar 5) untuk pengiriman(dispatching). 


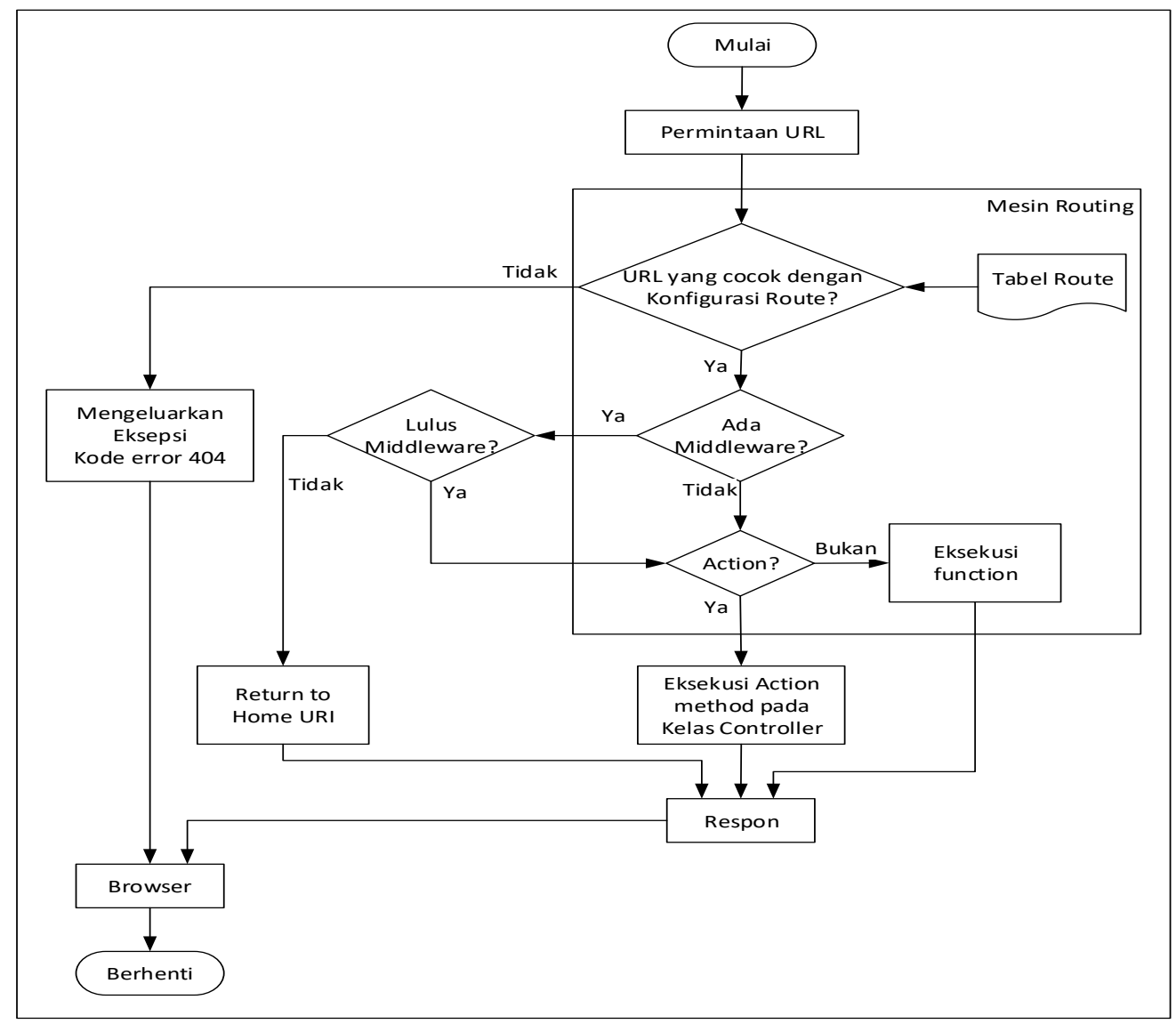

Gambar 5. Cara kerja routing pada Laravel

Penjelasan proses alur kerja routing pada Laravel 5.0 yaitu sebagai berikut:

1. Routing akan menerima permintaan URL dari browser

2. Routing akan mencari URL yang cocok dengan konfigurasi pada tabel route Jika ditemukan maka ke langkah selanjutnya, jika tidak ditemukan lanjut ke nomor 10.

3. Apakah terdapat middleware pada konfigurasi route? Jika terdapat middleware maka lanjut ke langkah no.4, jika tidak ditemukan middlewaare maka ke lanjut ke nomor 6 .

4. Uji kelulusan middleware pada mesin middleware Jika lulus maka lanjut ke nomor 6 , jika tidak maka ke langkah selanjutnya.

5. Redirect ke halaman home, lalu lanjut ke langkah

6. Cek apakah closure berupa action Jika bukan maka lanjut ke nomor 8 , Jika ya ke langkah selanjutnya.

7. Eksekusi actionmethod -nya pada kelas controller berdasarkan konfigurasi route tersebut, lalu lanjut ke nomor 9.

8. Eksekusi function pada konfigurasi route tersebut, kelangkah selanjutnya.

9. Mengeluarkan response, lalu lanjut ke nomor 11.

10. Mengeluarkan eksepsi kode error 404

11. Menampilkan ke browser

12. Berhenti 


\subsection{Perancangan}

\subsubsection{Aplikasi Menggunakanrouting Laravel}

Aplikasi ini dibuat untuk membuktikan kajian dari routing dengan framework Laravel 5.0.

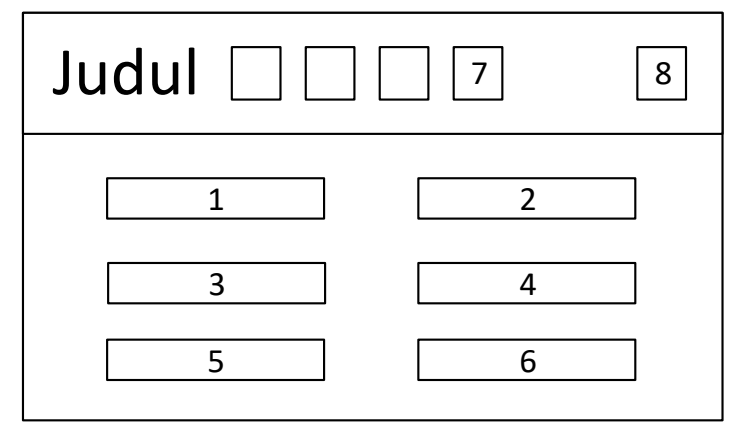

\section{Gambar 6. Skema menu utama pengujian routing Laravel}

Penjelasan Gambar 6 skema menu utama sebagai berikut:

Tombol 1 berisi pengujian untuk menguji routing yang berperan sebagai dirinya sendiri.Tombol 2 berisi pengujian untuk menguji routing yang berperan sebagai controller.Tombol 3 berisi pengujian untuk menguji routing yang dialiaskan.Tombol 4 berisi pengujian untuk menguji routing yang dikelompokkan.Tombol 5 berisi pengujian untuk menguji routingimplicitcontroller.Tombol 6 berisi pengujian untuk menguji routingrestfullresourcecontroller.Tombol 1, 2, 3, 4, 5, dan 6 menampilkan tampilan yang sama yaitu proses CRUD, tetapi terdapat perbedaan dari methodrouting -nya.Tombol 7 berisi pengujian untuk menguji routing dengan lokasi kelas controller ditentukan sendiri. Tombol ini menampilkan tampilan formlogin.Tombol 8 berisi pengujian untuk menguji routing dengan middlewareauth. Tombol ini menampilkan tampilan dengan teks header dan paragraf.

\subsubsection{Aplikasi konvensional tanpa skrip}

Aplikasi ini dibuat untuk membuktikan proses perhitungan langkah pembuatan URI secara konvensional tanpa menggunakan skrip. Maksud dari konvensional tanpa menggunakan skrip adalah pembuatan URI -nya tidak mengunakan skrip PHP ataupun skrip pada webserver Apache, tetapi langsung pada pembuatan direktori pada webserver untuk setiap URI -nya.

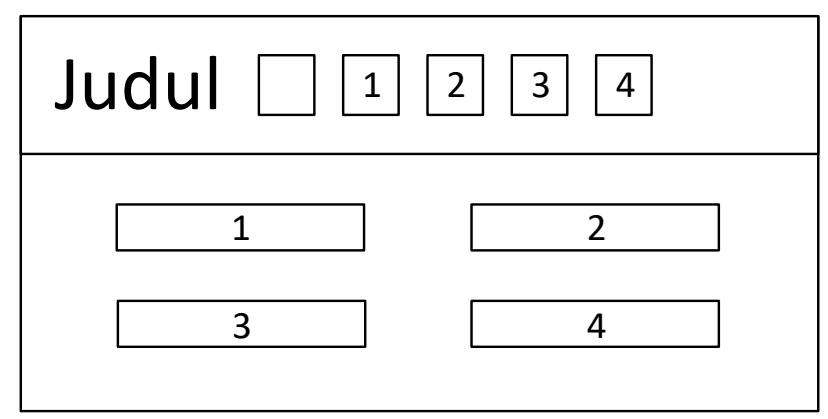

Gambar 7. Skema menu utama pengujian konvensional tanpa skrip

Penjelasan Gambar 7 skema menu utama sebagai berikut:

Halaman skema merupakan halaman pengujian untuk menguji membuat URI aplikasi web.Tombol 1 berisi pengujian untuk menguji URI berparamater. Tombol ini menampilkan 
tampilan yang membaca parameter yang di request dari URL browser. Tombol 2 berisi pengujian untuk menguji mengaliaskan URI. Tombol ini menampilkan tampilan-tampilan yang dialiaskan URI -nya.Tombol 3 berisi pengujian untuk menguji mengelompokkan URI. Tombol ini menampilkan tampillan-tampilan yang telah dikelompokkan URI -nya.Tombol 4 berisi pengujian untuk menguji proses CRUD. Tombol ini menampilkan tampilan daftar data, form untuk membuat data baru, melihat salah satu isi data, dan form untuk mengubah data.

\subsubsection{Aplikasi konvensional menggunakan skrip}

Aplikasi ini dibuat untuk membuktikan proses perhitungan langkah pembuatan URI secara konvensional yang menggunakan skrip. Maksud dari konvensional yang menggunakan skrip adalah pembuatan URI -nya mengunakan skrip pada webserver Apache dan skrip PHP, sehingga akan tampak seperti URI dari routing Laravel.

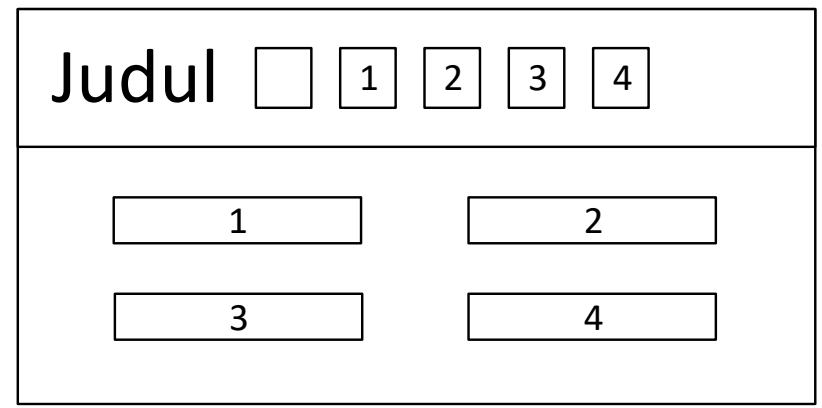

Gambar 8. Skema menu utama pengujian konvensional menggunakan skrip

Penjelasan Gambar 8 skema menu utama sebagai berikut:

Halaman skema merupakan halaman pengujian untuk menguji membuat URI aplikasi web.Tombol 1 berisi pengujian untuk menguji URI berparamater. Tombol ini menampilkan tampilan yang membaca parameter yang di request dari URL browser. Tombol 2 berisi pengujian untuk menguji mengaliaskan URI. Tombol ini menampilkan tampilan-tampilan yang dialiaskan URI -nya.Tombol 3 berisi pengujian untuk menguji mengelompokkan URI. Tombol ini menampilkan tampillan-tampilan yang telah dikelompokkan URI -nya.Tombol 4 berisi pengujian untuk menguji proses CRUD. Tombol ini menampilkan tampilan daftar data, form untuk membuat data baru, melihat salah satu isi data, dan form untuk mengubah data.

\subsection{Pengujian}

Pada tahap ini perlu diketahui kerangka pengujian terlebih dahulu, yaitu:

1. Pengujian syarat routing, pengujian ini bertujuan untuk mengetahui akibat-akibat yang terjadi jika terdapat perubahan dari syarat dalam menghadirkan dan berjalannya routing.

2. Pengujian peran routing, pengujian ini dilakukan untuk mengetahui pengaruh yang dihasilkan dari perbedaan peran routing.

3. Pengujian fitur routing, pengujian ini dilakukan pada beberapa fitur routing meliputi fitur alias routing, pengelompokkan routing, dan sekali definisi routing.

4. Pengujian jumlah langkah secara routing dan konvensional, pengujian ini dilakukan untuk mengukur jumlah proses atau langkah pembuatan URI terhadap routing Laravel dan cara konvensional yang menyerupai routing Laravel. 


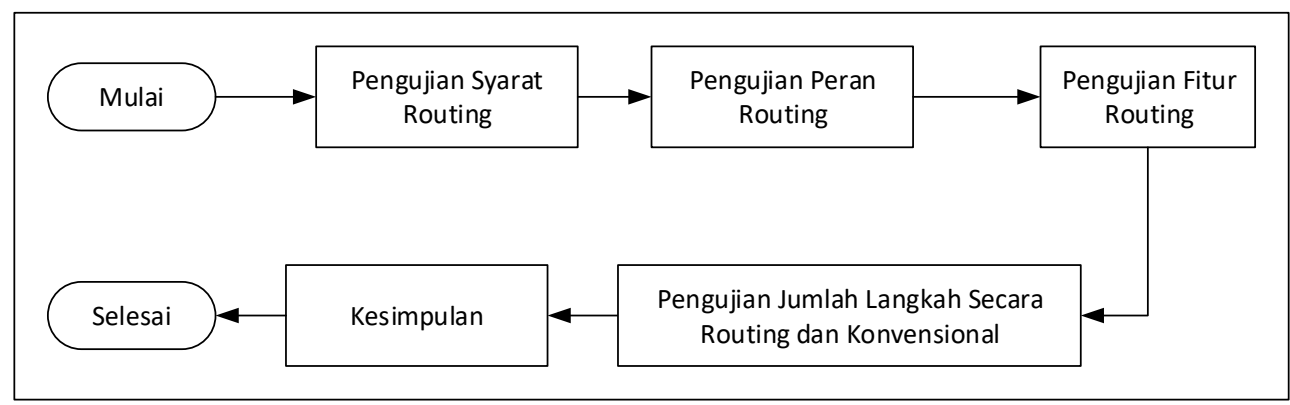

Gambar 5. Cara kerja routing pada Laravel

Pengujian routing Laravel dengan cara menggunakan aplikasi yang dibuat menggunakan Laravel. Sedangkan pengujian secara konvensional mengunakan aplikasi konvensional tanpa skrip (untuk menguji proses perhitungan konvensional tanpa skrip) dan aplikasi konvensional menggunakan skrip (untuk menguji proses perhitungan konvensional yang menggunakan skrip).

Tabel 1.Hasil perbandingan jumlah langkah secara routing Laravel dan konvesional

\begin{tabular}{|c|c|c|c|}
\hline Yang Dibandingkan & \multicolumn{2}{|c|}{ Secara Konvensional } & \multirow{2}{*}{$\begin{array}{c}\text { Routing } \\
\text { Laravel } \\
\text { (dalam } \\
\text { langkah) }\end{array}$} \\
\cline { 2 - 4 } & $\begin{array}{c}\text { Tanpa Skrip } \\
\text { (dalam } \\
\text { langkah) }\end{array}$ & $\begin{array}{c}\text { Dengan Skrip } \\
\text { (dalam } \\
\text { langkah) }\end{array}$ & 1 \\
\hline Membuat URI aplikasi web & 2 & 2 & 1 \\
\hline Membuat URI berparameter & 2 & 2 & 1 \\
\hline Mengaliaskan URI & 2 & 2 & 1 \\
\hline $\begin{array}{c}\text { Mengelompokkan URI - membuat URI } \\
\text { induk }\end{array}$ & 1 & 1 & 1 \\
\hline $\begin{array}{c}\text { Mengelompokkan URI - membuat URI } \\
\text { anggota }\end{array}$ & 2 & 2 & 1 \\
\hline Membuat URI untuk proses CRUD & 8 & 8 & \\
\hline
\end{tabular}

\section{KESIMPULAN}

Berdasarkan tabel 1 perbandingan jumlah langkah dalam membuat URI terhadap routing Laravel dan cara konvensional, bahwa routing pada Laravel 5.0 memiliki langkah sekali definisi jika dibandingkan tanpa routing pada saat membuat URI aplikasi web, membuat URI berparameter, meangaliaskan URI, mengelompokkan URI, dan membuat URI untuk proses CRUD.Untuk proses CRUD, Laravel menyediakan Restful Routing yang membuat developer mempersingkat langkahnya dalam membangun CRUD dengan satu baris deklarasi. Routing pada Laravel dapat berperan sebagai controlller, sehingga menggantikan fungsi kelas controller. Routing pada Laravel 5.0 terdapat fitur untuk keamanan ataupun mem- filterroute, dengan menggunakan fitur HTTP Middleware.Laravel menyediakan fitur implicitcontroller yang membuat cukup sekali deklarasi route -nya untuk berbagai macam action dalam controller.Peneliti tidak menemukan kekurangan dari pengunaan routing pada Laravel.Ada konsekuensi yang harus ditempuh yaitu developer harus memahami konsep routing pada Laravel tersebut. 


\section{DAFTAR RUJUKAN}

[1] B. Skvorc, "The Best PHP Framework for 2015: SitePoint Survey Results," 2015. [Online]. Available: http://www.sitepoint.com/best-php-framework-2015-sitepoint-surveyresults/. [Diakses 15 April 2015].

[2] F. Potencier, "Day 4: The Controller and the View," 2005. [Online]. Available: http://symfony.com/legacy/doc/jobeet/1_2/en/04?orm=Propel. [Diakses 26 April 2015].

[3] T. Otwell, "HTTP Routing - Laravel - The PHP Framework For Web Artisans," 2015. [Online]. Available: https://laravel.com/docs/5.0/routing. [Diakses 26 April 2015].

[4] M. Ehsan, "Architecture of Laravel Applications - Laravel Book," 2013. [Online]. Available: http://laravelbook.com/laravel-architecture/. [Diakses 26 April 2015].

[5] "Laravel 5 request lifecycle," $2016 . \quad$ [Online]. Available: http://www.phpcodehub.co.in/article/laravel-5-request-lifecycle-aid-10.html. [Diakses 2016 Juli 2016]. 